\title{
DESEMPENHO DE JARDINS CLONAIS DE OLIVEIRA OBTIDOS POR ESTAQUIA E ENXERTIA EM CORTES SUCESSIVOS
}

\section{PERFORMANCE OF THE CLONAL GARDENS OF THE OLIVE TREE OBTAINED BY CUTTING AND GRAFTS IN SUCCESSIVE CUTS}

\author{
Adelson Francisco de OLIVEIRA ${ }^{1}$ \\ João VIEIRA NETO \\ Fabíola VILLA ${ }^{3}$ \\ Luiz Fernando de Oliveira da SILVA ${ }^{4}$
}

\section{RESUMO}

O trabalho teve por objetivo avaliar o desempenho de jardins clonais de oliveira em cortes sucessivos visando sua propagação por estaquia. O estudo foi conduzido na Epamig em Maria da Fé (MG), Brasil. Os jardins clonais foram instalados em março de 2006, em sulcos com $40 \mathrm{~cm}$ de profundidade. Foram avaliadas duas cultivares (Ascolano 315 e Arbequina) e três anos de cortes (2007, 2008 e 2009). O ensaio foi conduzido em parcelas subdivididas no delineamento de blocos casualizados com cinco repetições. As parcelas experimentais foram constituídas de três linhas, espaçadas entre si em $1 \mathrm{~m}$, com três plantas em cada linha, $0,5 \mathrm{~m}$ uma da outra, totalizando nove plantas por parcela, sendo as avaliações realizadas nas três plantas mais vigorosas. Para avaliação, as três plantas foram podadas a $20 \mathrm{~cm}$ de altura do solo, após 12 meses de cultivo, sendo avaliados a altura da planta, diâmetro do tronco a $20 \mathrm{~cm}$ de altura do solo, comprimento médio de ramos, rendimento em número de estacas com quatro nós/dois pares de folhas e massa verde total acumulada. Em todas as variáveis avaliadas, melhores resultados foram observados em 'Ascolano 315', propagadas por estaquia. Os cortes sucessivos podem se estender por um período superior a três anos.

Palavras-chave: Olea europaea; propagação; produção de mudas.

\begin{abstract}
The objective of this work was to evaluate the performance of clonal olive tree gardens in successive cuts at its propagation by cutting. The study was conducted in the Epamig of Maria da Fé, Minas Gerais State, Brazil. The clonal garden was installed in March 2006, in grooves with $40 \mathrm{~cm}$ in depth. Two cultivars (Ascolano 315 and Arbequina) Were evaluated and cuts in three years $(2007,2008$ and 2009). The test was conducted in split plot in time in a randomized block design with five replications. The plots were composed of three lines, spaced between itself in one meter, three plants in each line, $0,5 \mathrm{~m}$ of one another, a total of nine plants per plot, being the evaluations carried through in three more vigorous plants. For evaluation, three plants were pruned to $20 \mathrm{~cm}$ height of the soil, after 12 months of cultivation, being evaluated the plants height, torso diameter the $20 \mathrm{~cm}$ height of the soil, average length of branches, yield of cutting number with four knots by leaves two pairs and total green mass accumulated. In all features evaluated, better results were observed in the 'Ascolano 315 ' by cutting. The successive cuts may be extended for three years higher period.
\end{abstract}

Key-words: Olea europaea; propagation; production of seedlings.

\footnotetext{
${ }^{1}$ D. Sc., Pesquisador da Empresa de Pesquisa Agropecuária de Minas Gerais (EPAMIG). Campus Universitário da Universidade Federal de Lavras (UFLA), Caixa Postal 176, Rodovia Lavras/IJACI, km 02, CEP: 37200-000, Lavras, Minas Gerais, Brasil. E-mail: adelson@epamig.br. Autor para correspondência

2 D. Sc., Pesquisador da Empresa de Pesquisa Agropecuária de Minas Gerais (EPAMIG), Maria da Fé, Minas Gerais, Brasil. E-mail: joaovieira@epamig.br.

${ }_{3}^{3}$ Pós-doutoranda em Fitotecnia, bolsista FAPEMIG/EPAMIG, Maria da Fé, Minas Gerais, Brasil. E-mail: fvilla2003@libero.it.

${ }^{4}$ Bolsista FAPEMIG/EPAMIG, Maria da Fé, Minas Gerais, Brasil. E-mail: luizfernando.agronomia@gmail.com.
} 
OLIVEIRA , A. F. et al. Desempenho de jardins clonais de oliveira ...

\section{INTRODUÇÃO}

Atualmente a oliveira (Olea europaea) é cultivada em todos os continentes. A importância dessa atividade agrícola está relacionada principalmente com a elaboração de azeite de oliva. Segundo dados do International Olive Oil Council (IOOC, 2007), a produção mundial da safra 2006/07 foi de aproximadamente 2,8 milhões de toneladas de azeite, sendo os principais países produtores a Espanha, Itália e Grécia.

$\mathrm{Na}$ região mediterrânea, em países da Comunidade Econômica Européia, são produzidos $79,8 \%$ do azeite de oliva mundial, destacando-a como maior produtora, sendo $42,9 \%$ obtidos na Espanha, $17,5 \%$ na Itália e $12,2 \%$ na Grécia, além de responder por quase $80 \%$ das exportações mundiais (Mesquita et al., 2006; IOOC, 2007).

O cultivo de oliveiras no Brasil é uma atividade agrícola recente e em expansão (Oliveira et al., 2009a). Anualmente são importadas pelo país 214 mil toneladas de azeitonas, sendo necessário o plantio de aproximadamente 11 milhões de mudas para produção desse volume, exigindo da pesquisa informações técnicas para sua produção (CONAB, 2009).

A estaquia e a enxertia são métodos de propagação utilizados na produção de mudas de oliveira. Essas técnicas vêm sendo aprimoradas nos últimos anos, principalmente o enraizamento de estacas semilenhosas sob nebulização intermitente (Pio et al., 2005; Caballero \& Del Rio, 2006; Oliveira et al., 2009b). Porém, requerem atenção para determinados fatores que influenciam no enraizamento, como disponibilidade e tipo de material vegetativo a ser utilizado e compatibilidade do porta-enxerto com a planta a ser enxertada (Oliveira et al., 2003; Oliveira et al., 2009b).

A implantação de jardins clonais com o objetivo de produzir material propagativo torna-se vantajoso, pois além de permitir a coleta de ramos durante todo o ano, podem apresentar caráter juvenil e vigor vegetativo, características estas favoráveis ao enraizamento. Segundo Hackett (1987) a juvenilidade é um fator importante em plantas lenhosas por afetar a capacidade de propagação vegetativa, além de proporcionar variações nas taxas e formas de crescimento, na qualidade e rapidez na formação de raízes, e também mudanças fisiológicas e bioquímicas, com a transição para o estágio maduro.

Diante do exposto, o objetivo do presente trabalho foi avaliar o desempenho de jardins clonais formados com mudas obtidas por estaquia e enxertia, sob cortes sucessivos em intervalos de 12 meses de cultivo, com 0 intuito de gerar informações sobre o ritmo de crescimento, vigor da planta e rendimento em número de estacas com quatro nós e dois pares de folhas, em duas cultivares de oliveira.

\section{MATERIAL E MÉTODOS}

O presente trabalho foi conduzido durante três anos consecutivos (2007, 2008 e 2009), na Fazenda Experimental da Epamig, localizada no município de Maria da Fé, micro-região da Serra da Mantiqueira, sul de Minas Gerais.

O município de Maria da Fé apresenta uma classificação climática, segundo Köppen, do tipo Cwb, ou seja, clima temperado chuvoso (mesotérmico), também chamado subtropical de altitude. Caracteriza-se por apresentar uma temperatura média anual em torno de $17{ }^{\circ} \mathrm{C}$, temperatura média máxima de $23,3{ }^{\circ} \mathrm{C}$ e mínima média de $10,1^{\circ} \mathrm{C}$, precipitação anual de $1.738,6$ $\mathrm{mm}$ e altitude média de $1.276 \mathrm{~m}$, com predomínio de relevo ondulado (Minas Gerais, 2001; ALMG, 2005).

Os jardins clonais foram instalados em março de 2006, em área previamente corrigida de acordo com análise de fertilidade para $\mathrm{pH}$ em torno de 6,0, utilizando-se calcário dolomítico (PRNT $100 \%$ ). Foram avaliadas duas cultivares de oliveira (Ascolano 315 e Arbequina), três cortes sucessivos (em março, referente aos anos de avaliação) e dois métodos de propagação (estaquia e enxertia).

$O$ delineamento estatístico utilizado foi o de parcelas subdivididas com cinco repetições. As parcelas experimentais foram constituídas de três linhas, espaçadas entre si em $1 \mathrm{~m}$, com três plantas em cada linha, 0,5 $\mathrm{m}$ uma da outra, totalizando nove plantas por parcela, sendo as avaliações realizadas nas três plantas mais vigorosas.

As mudas de oliveira foram obtidas por estaquia e enxertia. Para a realização da estaquia foram utilizadas estacas semilenhosas tratadas com AIB em câmara de nebulização intermitente, conforme descrito por Caballero \& Del Río (2006). Para as mudas enxertadas foram utilizados portaenxertos de plantas oriundas de sementes das próprias variedades.

Os plantios foram realizados em sulcos com $40 \mathrm{~cm}$ de profundidade, que receberam com antecedência de 60 dias, $15 \mathrm{dm}^{-3}$ da mistura esterco de curral + esterco de galinha, na proporção de 1:1 (devidamente misturados com a terra de plantio), enriquecidos com $1,5 \mathrm{~kg}$ de superfosfato simples em $1 \mathrm{~m}$ linear de sulco. Em todas as parcelas experimentais foram aplicados, mensalmente via pulverização foliar, adubação de macro e micronutrientes na concentração de $14 \%$ de $\mathrm{N}$ (amoniacal $0,7 \%$, nítrica $8 \%$ e amídica 5,3\%), $4 \%$ de $\mathrm{P}_{2} \mathrm{O}_{5}, 20 \%$ de $\mathrm{K}_{2} \mathrm{O}, 2 \%$ de $\mathrm{Mg}, 2 \%$ de $\mathrm{B}$ e $0,05 \%$ de $\mathrm{Mn}$.

As plantas do jardim clonal receberam irrigação localizada sempre que necessário, em quantidades suficientes para manter 0 solo umedecido. Foram realizados os tratamentos fitossanitários usuais, utilizando produtos específicos, de acordo com a necessidade, mantendo também as áreas livres de invasoras.

Para avaliação, as três plantas foram 
OLIVEIRA , A. F. et al. Desempenho de jardins clonais de oliveira ...

podadas a $20 \mathrm{~cm}$ de altura do solo, a cada 12 meses de cultivo, sendo avaliados a altura da planta, diâmetro do tronco a $20 \mathrm{~cm}$ de altura do solo, comprimento médio de ramos, rendimento em número de estacas com quatro nós e dois pares de folhas (em torno de $12 \mathrm{~cm}$ de comprimento) e massa verde total acumulada.

Os dados coletados foram analisados estatisticamente utilizando o programa NTIA (EMBRAPA, 1997). Foi aplicada a análise de variância, com teste $F$ para verificar os efeitos principais e da interação entre os fatores e confirmado efeito significativo foi aplicado o teste de Tukey para comparar as médias. Para o número de estacas por planta foi aplicada a transformação $(\mathrm{x}+0,5)^{1 / 2}$, com finalidade de proporcionar a distribuição normal das médias observadas. Em todas as análises foram adotados $5 \%$ de probabilidade de erro.

\section{RESULTADOS E DISCUSSÃO}

A altura das plantas foi influenciada pela cultivar e pelo número de cortes, separadamente, sendo maiores na 'Ascolano 315' e no primeiro corte, alcançando respectivamente 1,835 e 1,913 m de altura (Tabela 1).

TABELA 1 - Altura média de plantas de oliveira em jardins clonais sob cortes sucessivos. Maria da Fé, MG, 2009.

\begin{tabular}{cc}
\hline Cultivares & Altura $(\mathrm{m})$ \\
\hline Ascolano 315 & $1,835 \mathrm{a}^{*}$ \\
Arbequina & $1,515 \mathrm{~b}$ \\
\hline Épocas de corte & $1,913 \mathrm{a}$ \\
\hline 2007 & $1,171 \mathrm{~b}$ \\
2008 & $1,947 \mathrm{a}$ \\
2009 & 21,27 \\
\hline C.V. $(\%)$ & 20 Tukey a $5 \%$ deprobilide.
\end{tabular}

*Médias seguidas da mesma letra minúscula na vertical não diferem entre si pelo teste de Tukey a $5 \%$ de probabilidade.

Observa-se, na Tabela 2 que em ambas as cultivares o terceiro corte proporcionou melhor resultado de diâmetro do tronco em relação as demais e a cultivar Ascolano 315 superou em 17\% o diâmetro do tronco da 'Arbequina' no terceiro corte. Segundo Del Rio \& Caballero (2006), a altura e o diâmetro da planta são parâmetros que fazem referência ao vigor da árvore de oliveira, definindo o seu tamanho definitivo. Esses autores atribuem à variedade a principal causa da variabilidade observada para esse critério agronômico.

TABELA 2 - Diâmetro médio do tronco para cultivares de oliveira e cortes sucessivos em jardins clonais. Maria da Fé, MG, 2009.

\begin{tabular}{cc}
\hline Cultivares & Diâmetro $(\mathrm{mm})$ \\
\hline Ascolano 315 & $5,183 \mathrm{a}^{*}$ \\
Arbequina & $4,438 \mathrm{~b}$ \\
\hline Épocas de corte & \\
\hline 2007 & $4,165 \mathrm{~b}$ \\
2008 & $4,574 \mathrm{~b}$ \\
2009 & $5,690 \mathrm{a}$ \\
\hline C.V. $(\%)$ & 24,0 \\
\hline
\end{tabular}

*Médias seguidas da mesma letra minúscula na vertical não diferem entre si pelo teste de Tukey a $5 \%$ de probabilidade. 
OLIVEIRA , A. F. et al. Desempenho de jardins clonais de oliveira ...

As variáveis agronômicas, como altura de plantas, formato de frutos e vigor diferem significativamente para cultivares de mesa e para azeite (IOOC, 2007). O vigor de uma planta resume-se em espessura x largura x altura da planta. Sendo assim, o vigor da cultivar Ascolano 315 foi superior ao apresentado pela cultivar Arbequina. Esta última é muito apreciada pela precoce entrada em produção, elevada produtividade, bom rendimento graxo e excelente qualidade do azeite produzido, porém com baixa estabilidade (Coutinho et al., 2007). Devido ao seu baixo vigor vegetativo é amplamente utilizada em sistema de plantio superintensivo em todo mundo, especialmente na Argentina, Chile e Espanha (Garcia \& Lacarte, 2008; De La Rosa et al., 2007; Pastor et al., 2005).

Em estudos com poda de formação da cultivar Cornicabra, verificou-se através de 3 cortes consecutivos, maior diâmetro de tronco a $30 \mathrm{~cm}$ do solo, em plantas de oliveira no terceiro ano de corte (López et al., 2003). Os mesmos autores confirmaram que o volume da copa destas árvores foram maiores no primeiro e segundo ano de corte das estacas.

Quanto ao comprimento médio dos ramos, os resultados foram semelhantes aos observados para o diâmetro do tronco, ou seja, a cultivar Ascolano 315 teve maior comprimento médio de ramos em relação a cultivar Arbequina e melhores resultados foram observados no terceiro corte.

Em relação a massa verde total acumulada, melhores resultados foram observados na cultivar Ascolano 315, por estaquia e no terceiro corte (Tabelas 3, 4,5 e 6). Observou-se pelos resultados da análise de variância que houve efeito significativo nas interações duplas (época $x$ cultivar, tipos de obtenção $x$ época e tipos de obtenção $x$ cultivar) para o rendimento do número de estacas $e$ massa verde total das plantas de oliveira.

TABELA 3 - Comprimento médio dos ramos para cultivares de oliveira e cortes sucessivos em jardins clonais. Maria da Fé, MG, 2009.

\begin{tabular}{cc}
\hline Cultivares & Comprimento $(\mathrm{m})$ \\
\hline Ascolano 315 & $1,029 \mathrm{a}^{*}$ \\
Arbequina & $0,886 \mathrm{~b}$ \\
\hline Época de corte & \\
\hline 2007 & $0,816 \mathrm{c}$ \\
2008 & $0,947 \mathrm{~b}$ \\
2009 & $1,109 \mathrm{a}$ \\
\hline C.V. (\%) & 23,95 \\
\hline
\end{tabular}

*Médias não seguidas da mesma letra minúscula na vertical diferem entre si pelo teste de Tukey a $5 \%$ de probabilidade.

TABELA 4 - Médias da massa verde total acumulada $(\mathrm{kg})$ para cultivares de oliveira e cortes sucessivos em jardins clonais. Maria da Fé, MG, 2009.

\begin{tabular}{lccc}
\hline & & \multicolumn{3}{c}{ Épocas de corte } & \\
\cline { 2 - 4 } Cultivares & 2007 & 2008 & 2009 \\
\hline Ascolano 315 & $1,257 \mathrm{bA}^{*}$ & $1,064 \mathrm{cB}$ & $1,695 \mathrm{aA}$ \\
Arbequina & $1,010 \mathrm{bB}$ & $0,999 \mathrm{bC}$ & $1,211 \mathrm{aB}$ \\
\hline C.V. $(\%)$ & & 35,07 & \\
\hline
\end{tabular}

*Médias não seguidas da mesma letra minúscula vertical e maiúscula na horizontal diferem entre si pelo teste de Tukey a $5 \%$ de probabilidade. 
OLIVEIRA, A. F. et al. Desempenho de jardins clonais de oliveira ...

TABELA 5 - Médias da massa verde total acumulada $(\mathrm{kg})$ para métodos de obtenção de mudas e cortes sucessivos em jardins clonais. Maria da Fé, MG, 2009.

\begin{tabular}{cccc}
\hline \multirow{2}{*}{ Métodos de obtenção } & \multicolumn{3}{c}{ Épocas de corte } \\
\cline { 2 - 4 } & 2007 & 2008 & 2009 \\
\hline Estaquia & $1,159 \mathrm{bC}{ }^{*}$ & $1,037 \mathrm{cC}$ & $1,566 \mathrm{aA}$ \\
Enxertia & $1,107 \mathrm{bC}$ & $1,026 \mathrm{cC}$ & $1,341 \mathrm{aB}$ \\
\hline
\end{tabular}

C.V. $(\%)$

*Médias não seguidas da mesma letra minúscula na vertical e maiúscula na horizontal diferem entre si pelo teste de Tukey a $5 \%$ de probabilidade.

TABELA 6 - Médias da massa verde total acumulada $(\mathrm{kg})$ para cultivares de oliveira e métodos de obtenção. Maria da Fé, MG, 2009.

\begin{tabular}{ccc}
\hline \multirow{2}{*}{ Cultivares } & \multicolumn{2}{c}{ Métodos de obtenção } \\
\cline { 2 - 3 } & Estaquia & Enxertia \\
\hline Arbequina & $1,067 \mathrm{bC} *$ & $1,079 \mathrm{bC}$ \\
Ascolano 315 & $1,441 \mathrm{aA}$ & $1,236 \mathrm{aB}$ \\
\hline
\end{tabular}

C.V. $(\%) \quad 18,24$

*Médias não seguidas da mesma letra minúscula na vertical e maiúscula na horizontal diferem entre si pelo teste de Tukey a $5 \%$ de probabilidade.

A quantidade de estacas com quatro nós e dois pares de folhas retiradas da parte aérea a cultivar Ascolano 315, independentemente do efeito de cortes, teve melhores resultados em relação a cultivar Arbequina em ambos os métodos de propagação (Tabela 7).

TABELA 7 - Rendimento em número de estacas obtidas em oliveiras 'Ascolano 315' e 'Arbequina' fornecedoras de material propagativo para propagação através de estaquia e enxertia, em jardins clonais. Maria da Fé, MG, 2009.

\begin{tabular}{lcl}
\hline \multirow{2}{*}{ Cultivares } & \multicolumn{2}{c}{ Número médio de estacas } \\
\cline { 2 - 3 } & Enxertia & Estaquia \\
\hline Ascolano 315 & $7,662 \mathrm{aB}^{*}$ & $9,352 \mathrm{aA}$ \\
Arbequina & $6,315 \mathrm{bB}$ & $6,217 \mathrm{bB}$
\end{tabular}

C.V. (\%) 34,81

${ }^{*}$ Médias seguidas da mesma letra minúscula na vertical e maiúscula na horizontal não diferem entre si pelo teste de Tukey a $5 \%$ de probabilidade.

Esta diferença nas médias se deve ao fato da 'Ascolano 315' apresentar, caracteristicamente, hábito de crescimento mais intenso, quando comparada com o cultivar Arbequina. Ao trabalhar com a caracterização morfológica de cultivares de oliveira do banco de germoplasma da Epamig em Maria da Fé, Oliveira et al. (2006) observaram que de todas as cultivares analisadas, 'Ascolano 315' se destacou com plantas mais altas, sendo por isso considerada muito vigorosa. Estudos recentes de adaptação de cultivares no norte de Minas Gerais mostraram melhor rendimento agronômico em plantas de um ano dessa mesma cultivar (Oliveira et al., 2008).

Ainda é possível observar que melhores resultados foram obtidos através da estaquia corroborando Oliveira et al. (2009a). Resultados semelhantes foram encontrados em trabalho realizado por Bordin et al. (2005) estudando desenvolvimento vegetativo de mudas de acerola propagadas através de enxertia e estaquia. Neste, observou-se que as plantas oriundas de estaquia apresentaram melhores resultados em todas as características analisadas. Segundo Hartmann et al. (2002), a superioridade no desenvolvimento da parte aérea apresentada pela estaquia comparada com a enxertia (porta-enxerto oriundo de sementes) pode estar relacionada aos maiores níveis de carboidratos presentes nos ramos que serviram como fonte de energia para auxiliar no desenvolvimento das mudas.

Pode-se observar que o terceiro corte proporcionou maior número de estacas (Tabela 8), indicando que os dois cultivares possuem boa capacidade de rebrota quando submetidas a cortes 
OLIVEIRA , A. F. et al. Desempenho de jardins clonais de oliveira ...

sucessivos em intervalos anuais. Mais uma vez a estaquia se destaca no terceiro corte, sendo 1,30 vezes maior que a enxertia. O método de estaquia torna-se viável em situações em que se necessita de rápida produção de mudas. Agrega-se a isto, o benefício da não utilização de porta-enxertos, evitando problemas como incompatibilidade entre copa e porta-enxertos e intolerância de determinados porta-enxertos à viroses.

TABELA 8 - Número médio de estacas de 'Ascolano 315' e 'Arbequina', obtidas de enxertia e estaquia. Maria da Fé, MG, 2009.

\begin{tabular}{ccccc}
\hline Épocas de corte & \multicolumn{2}{c}{ Cultivares } & \multicolumn{2}{c}{ Métodos de obtenção } \\
\hline \multirow{2}{*}{2007} & Ascolano 315 & Arbequina & Enxertia & Estaquia \\
\cline { 2 - 5 } 2008 & $8,373 \mathrm{bB}^{*}$ & $6,101 \mathrm{bC}$ & $7,038 \mathrm{aB}$ & $7,436 \mathrm{bB}$ \\
2009 & $6,114 \mathrm{cC}$ & $5,382 \mathrm{bC}$ & $5,944 \mathrm{bC}$ & $5,552 \mathrm{cC}$ \\
& $11,033 \mathrm{aA}$ & $7,315 \mathrm{aB}$ & $7,982 \mathrm{aB}^{*}$ & $10,366 \mathrm{aA}$ \\
\end{tabular}

C.V. (\%)

34,81

*Médias seguidas da mesma letra minúscula na vertical e maiúscula na horizontal não diferem entre si pelo teste de Tukey a $5 \%$ de probabilidade.

Esses resultados sugerem que se utilize a estaquia como método de propagação da oliveira e que os cortes sucessivos podem se estender por um período superior a três anos, sendo necessária a continuidade das avaliações experimentais até que se verifique uma queda significativa nos parâmetros avaliados, principalmente no rendimento em número de estacas, inviabilizando a manutenção do jardim clonal em nível comercial. Esta variável é um importante índice técnico, interferindo diretamente no planejamento de produção de mudas, sendo necessária no dimensionamento de viveiros de mudas.

Em estudos de jardim clonal de 20 clones oriundos de matrizes híbridas de Eucalipto, Rosse et al. (1997) constataram que a capacidade de brotação das cepas e o enraizamento das estacas foram influenciadas pela época de abate das árvores e pela precipitação média anual. $\mathrm{O}$ mesmo foi observado por Perrando \& Corder (2006) em plantas de acácia-negra (Acacia mearnsii).

A importância da seleção de matrizes pelo volume da parte aérea, ausência de patógenos e susceptibilidade a doenças, permitiu que a propagação vegetativa se tornasse o principal método de reprodução clonal de árvores selecionadas (Haag, 1983). Dentre estes métodos, a estaquia é ainda, a técnica de maior viabilidade econômica para o estabelecimento de plantios clonais de espécies florestais (Paiva \& Gomes, 1993).

O potencial de regeneração de touças em Eucalyptus é, normalmente, afetado pelas condições edafoclimáticas da região de plantio, pelas alternativas de manejo e por determinantes genéticos. A interação desses fatores pode influenciar tanto o potencial inicial de regeneração, fazendo com que falhas, após cada corte, aumentem, resultando em oscilações ao final de cada corte de ramos (Zuffellato-Ribas \& Rodrigues, 2001).

No entanto, salienta-se que o comportamento das cultivares aqui estudados diz respeito às características intrínsecas aos genótipos estudados, não sendo motivo de exclusão de um em detrimento ao outro. Ambos os materiais são importantes na implantação comercial da olivicultura no sul de Minas Gerais, pois as duas cultivares estudadas destinam-se para mesa (Ascolano 315) e produção de azeite (Arbequina). A utilização de jardins clonais para produção de estacas vem sendo amplamente utilizada em cafeeiros, frutíferas em geral e principalmente em eucaliptais. Com o atual estudo, pretende-se empregar esta técnica em plantios comerciais brasileiros de oliveira.

\section{CONCLUSÕES}

Os resultados deste estudo indicam que: i) A cultivar Ascolano 315 apresentou maior desempenho de jardim clonal formado com mudas obtidas por estaquia e enxertia que a cultivar Arbequina em todas as características agronômicas avaliadas. ii) Os cortes sucessivos podem se estender por um período superior a três anos, pois as plantas das duas cultivares, apresentaram boa resposta a rebrota, estando o jardim clonal em pleno desenvolvimento. iii) A estaquia é o melhor método para formação dos jardins clonais para ambos os cultivares.

\section{AGRADECIMENTOS}

À Fundação de Amparo a Pesquisa do Estado de Minas Gerais (FAPEMIG) pelo apoio financeiro na execução desse trabalho - CAG APQ 0493-07. 
OLIVEIRA , A. F. et al. Desempenho de jardins clonais de oliveira ...

\section{REFERÊNCIAS}

1. ASSEMBLÉIA LEGISLATIVA DO ESTADO DE MINAS GERAIS (ALMG). Banco de dados. Belo Horizonte, 2005. Disponível em: <http://www.almg.gov.br/index.asp?grupo=estado\&diretorio=munmg\&arquivo=municipios>. Acesso em: 22 jul. 2008.

2. BORDIN, I. et al. Desenvolvimento de mudas de aceroleira propagadas por estacas e sementes em solo compactado. Ciência Rural, v. 35, n. 3, p. 530-536, 2005.

3. CABALLERO, J. M.; DEL RÍO, C. Propagação da oliveira por enraizamento de estacas semilenhosas sob nebulização. Informe Agropecuário, v. 27, n. 231, p. 33-38, 2006.

4. COMPANHIA NACIONAL DE ABASTECIMENTO (CONAB). Indicadores da agropecuária. Brasília, 2009. Disponível em: <http://www.conab.gov.br/conabweb/index.php?PAG=212>. Acesso em: 14 set. 2009.

5. COUTINHO, E. F.; JORGE, R. O.; COSTA, V. B. Cultivares de oliveira. In: COUTINHO, E. F. (Ed.). A cultura da oliveira. Pelotas: EMBRAPA, 2007. p. 39-49.

6. DEL RIO, C.; CABALLERO, J. M. Caracterização de variedades de oliveira no Banco Mundial de Germoplasma de Córdoba - Espanha. Informe Agropecuário, v. 27, n. 231, p. 18-26, 2006.

7. De La ROSA, R. et al. Olival superintensivo - realidade ou utopia? Revista de Ciências Agrárias, v. 30, n. 1, p. 546551,2007

8. EMPRESA BRASILEIRA DE PESQUISA AGROPECUÁRIA (EMBRAPA). Ambiente de software NTIA, versão 4.2.2 manual do usuário - ferramental estatístico. Campinas: EMBRAPA/CNPTIA, 1997. 258 p.

9. GARCIA, X. R.; LACARTE, J. M. Notas sobre plantaciones de olivos super intensivas en Chile. Fruticultura Profesional, n. 174, p. 30-37, 2008.

10. HAAG, H. P. Nutrição mineral de Eucalyptus, Pinus, Araucaria e Gmelina no Brasil. Campinas: Fundação Cargil, 1983. $101 \mathrm{p}$.

11. HACKETT, W.P. Donor plant maturation and adventitious root formation. In: DAVIES, T.D.; HAISSIG, B.E.; SANKHLA, N. (Eds.) Adventitious root formation in cuttings. Portland: Discorides, 1987. p. 11-28. (Advances in Plants Sciences Serie, 2).

12. HARTMANN, H. T. et al. Plant propagation: principles and practices. 7. ed. New Jersey: Prentice Hall, 2002.880 p.

13. INTERNACIONAL OLIVE OIL CONCIL (IOOC). Word olive oil figures: production. 2007. Disponível em: <http:/l www.internationaloliveoil.org/web/aa-ingles/corp/AreasActivitie/economics/AreasActivitie.html>. Acesso em: 30 abr. 2009

14. LÓPEZ, D. P.; ELCOROBARRUTIA, F. J. R.; RAMOS, N. O. Respuesta de un olivar cv. 'Cornicabra' a distintos momentos de la primera poda de formación en Ciudad Real. 2003. Disponível em: <http://www.expoliva.com/ expoliva2003/simposium/com.asp?anio=2003\&codigo=OLI>. Acesso em: 30 abr. 2009.

15. MESQUITA, D. L.; OLIVEIRA, A. F.; MESQUITA, H. A. Aspectos econômicos da produção e comercialização do azeite de oliva e azeitona. Informe Agropecuário, v. 27, n. 231, p. 7-12, 2006.

16. MINAS GERAIS. Fundação João Pinheiro. Anuário estatístico de Minas Gerais. Belo Horizonte:, 2001. Disponível em: <http://www.fjp.mg.gov.br/produtos/cei/anuario.pdf>. Acesso em: 10 nov. 2009.

17. OLIVEIRA, A. F. et al. Influência do número de nós em estacas semilenhosas de oliveira (Olea europaea L.) no enraizamento sob câmara de nebulização. Ciência Agrotecnologia, v. 27, n. 2, p. 332-338, 2003.

18. OLIVEIRA, A. F. et al. Rendimento agronômico de variedades de oliveira (Olea europaea L.) no norte de Minas Gerais. In: CONGRESSO BRASILEIRO DE FRUTICULTURA, 20., 2008, Vitória. Anais...Vitória: Incaper, 2008.

19. OLIVEIRA, A.F. et al. Pioneirismo marca pesquisa sobre oliveira em Minas Gerais. Informe Agropecuário, v.30, n. especial, p.109-117, 2009a.

20. OLIVEIRA, A. F. et al. Estaquia de oliveira em diferentes épocas, substratos e doses de AIB diluído em NaOH e álcool. Ciência e Agrotecnologia, v. 33, n. 1, p. 79-85, 2009b.

21. OLIVEIRA, A. F.; ANTUNES, L. E. C.; SCHUCH, M. W. Caracterização morfológica de cultivares de oliveira em coleção e considerações sobre o seu cultivo no Brasil. Informe Agropecuário, v. 27, n. 231, p. 55-62, 2006.

22. PAIVA, H. N.; GOMES, J. M. Propagação vegetativa de espécies florestais. Viçosa: Universidade Federal de Viçosa, 1995. $40 \mathrm{p}$.

23. PASTOR, M.; VEGA, V.; HIDALGO, J. C. Ensayos en plantaciones de olivar superintensivas e intensivas. Vida Rural n. 218, p. 30-40, 2005.

24. PERRANDO, E. R.; CORDER, M. P. M. Rebrota de cepas de Acacia mearnsii em diferentes idades, épocas do ano e alturas de corte. Pesquisa Agropecuária Brasileira, v. 41, n. 4, p. 555-562, 2006

25. PIO, R. et al. Enraizamento de diferentes tipos de estacas de oliveira (Olea europaea L.) utilizando-se ácido indolbutírico. Ciência e Agrotecnologia, v. 29, n. 3, p. 562-567, 2005.

26. ROSSE, L. N. et al. Influência da idade e da época de abate na brotação das cepas e no enraizamento de estacas em clones de Eucalyptus sp. Revista Cerne, v. 3, n. 1, p. 109-119, 1997

27. ZUFFELLATO-RIBAS, K. C.; RODRIGUES, J. D. Relações entre épocas do ano e diferentes concentrações de ácido indol butírico no enraizamento de estacas de Eucalyptus grandis. Boletim de Pesquisa Florestal, n .42, p. 71-80, 2001.

Recebido em 29/09/2009

Aceito em 29/04/2010 
